\title{
$8-2018$
}

\section{Manganese Oxide/Hemin-Functionalized Graphene as a Platform for Peroxynitrite Sensing}

\author{
Haitham F. Kalil \\ Cleveland State University, h.kalil@csuohio.edu \\ Shaimaa Maher \\ Cleveland State University \\ Tiyash Bose \\ Cleveland State University \\ Mekki Bayachou \\ Cleveland State University, M.BAYACHOU@csuohio.edu
}

Follow this and additional works at: https://engagedscholarship.csuohio.edu/scichem_facpub

Part of the Analytical Chemistry Commons, and the Biochemistry Commons

How does access to this work benefit you? Let us know!

\section{Recommended Citation}

Kalil, Haitham F.; Maher, Shaimaa; Bose, Tiyash; and Bayachou, Mekki, "Manganese Oxide/HeminFunctionalized Graphene as a Platform for Peroxynitrite Sensing" (2018). Chemistry Faculty Publications. 493.

https://engagedscholarship.csuohio.edu/scichem_facpub/493

This Article is brought to you for free and open access by the Chemistry Department at EngagedScholarship@CSU. It has been accepted for inclusion in Chemistry Faculty Publications by an authorized administrator of EngagedScholarship@CSU. For more information, please contact library.es@csuohio.edu. 


\title{
Manganese Oxide/Hemin-Functionalized Graphene as a Platform for Peroxynitrite Sensing
}

\author{
Haitham Kalil, Shaimaa Maher, Tiyash Bose, and Mekki Bayacho
}

Recent clinical research indicates that the cytotoxicity of peroxynitrite $\left(\mathrm{ONOO}^{-}, \mathrm{PON}\right)$ plays an important role in several pathologies including cardiovascular dysfunctions and other diseases triggered by oxidative stress. ${ }^{1-8}$ Peroxynitrite is a potent oxidative and/or nitrosative agent produced from the diffusion-controlled reaction between nitric oxide radical ( $\mathrm{NO}$ ) and superoxide anion-radical $\left(\mathrm{O}_{2}{ }^{-}\right)$. It is a well-known member of the reactive oxygen-nitrogen species family. ${ }^{9,10}$ This non-radical metabolite attacks vital components in cells and initiates deleterious effects via direct and indirect interactions. Peroxynitrite reacts directly with lipids, DNA, and proteins, and indirectly triggers several radical chain reactions. ${ }^{10,11}$ The elevation of peroxynitrite levels is associated with chronic inflammatory disorders including neurological and vascular diseases, as well as many other pathophysiological conditions. ${ }^{3,4 \cdot 10.12-15}$ Hence, the precise quantification of this analyte in biological systems is of paramount importance not only to understand the genesis and development of diseases at the tissue/cellular level. but also to assess potential therapies and understand its associated reaction mechanisms. Although some progress has being achieved in terms of peroxynitrite detection and quantification, the techniques of detection are still relatively limited. This deficiency is due to complicated pretreatment, low selectivity, as well as other technical problems. ${ }^{10.16}$ Fluorescence, chemiluminescence, electron spin resonance, and immunohistochemistry methods are indirect since they rely on the measurement of secondary species derived from oxidation or nitration reactions mediated by peroxynitrite. ${ }^{17-19}$ These indirect methods are of course costly, relatively laborious. and generally suffer from poor sensitivity and low selectivity. Thus, developing sensitive. selective. fast-responding. and direct detection methods is highly desirable.

Graphene nanosheets have become very attractive as an interface material for electrochemical sensing due to their unique physical and chemical properties. Graphene is a single atomic layer of graphite arranged in a two-dimensional structure. ${ }^{20-22}$ Its $\mathrm{sp}^{2}$ hybridization coupled with its ultra-thin atomic thickness accounts for graphene's unique properties and wide applications. ${ }^{23-35}$ Graphene can combine with substrates by either $\pi-\pi$ stacking or cation- $\pi$ interaction through catalytic metallic centers. ${ }^{33,36}$ Graphene modification, whether by metal decoration or nonmetal functionality, opens possibilities for its use in catalysis and sensor applications.

Electrochemical detection of analytes such as peroxynitrite at an interface generally offers real-time measurements using simple methods with minimum sample preparation. Metalloporphyrins-modified glassy carbon electrodes (GCE) have shown significant electrocatalytic properties toward peroxynitrite detection, particularly heminmodified GCE. Manganese phthalocyanine electrodeposited on platinum microelectrodes, also showed a significant increase in electrode sensitivity toward peroxynitrite. Both metalloporphyrins and phthalocyanine compounds have been used as electrochemical interfaces for peroxynitrite detection and were used as such or in a combination with graphene nanostructures. ${ }^{18,37-42}$

Several electrochemical sensors based on manganese phthalocyanine, cyanocobalamin, and hemin have been developed to detect peroxynitrite. ${ }^{17.40 .43}$ Amatore and co-workers used a platinized carbon microelectrode under physiological conditions. ${ }^{44}$ They were able to detect the signature of one-electron oxidation of peroxynitrite released under oxidative stress at the level of a living cell. ${ }^{44}$ Bedioui's group used a platinum ultramicroelectrode electrochemically modified with manganese tetraamino-phthalocyanine films for the detection of peroxynitrite in alkaline solutions $(\mathrm{pH}=10.2){ }^{43,45}$ The reported sensitivity of the modified sensor was $14.6 \mathrm{nA} / \mu \mathrm{M}$ with a limit of detection of $5 \mu \mathrm{M}$. On the other hand. Wang and Chen showed that electropolymerized cyanocobalamin films on glassy carbon can be used for the electrochemical detection of peroxynitrite at $\mathrm{pH}$ of 9.2. ${ }^{17}$ Apparently, the polymerized cyanocobalamin layer catalyzes the electrochemical oxidation of peroxynitrite at the surface of the electrode. ${ }^{17}$ Our group used electropolymerized 3,4-ethylenedioxythiophene (PEDOT)-hemin film on carbon fiber electrodes to detect and measure PON. ${ }^{46}$ Later, hemin-reduced graphene oxide material was used at an electrode interface for peroxynitrite detection. ${ }^{18}$ In this work, we examine the electrocatalytic activity of hemin-reduced graphene oxide material that is further modified with manganese oxide nanoparticles toward PON catalytic detection. Graphene oxide is used as a scaffold and is modified with needle-like $\mathrm{MnO}_{2}$ nanostructures followed by hemin functionalization as reported before. $^{18}$ 
The graphene-hemin nanomaterial modified with needle-like manganese oxide nanoparticles was formed and cast on carbon electrodes. We characterized the morphology and composition of this material using scanning electron microscopy (SEM), energy dispersive X-ray analysis (EDX), and X-ray photoelectron spectroscopy (XPS), and absorption spectroscopy. Finally, we investigated the electrochemical catalytic activity of the prepared interfaces using cyclic voltammetry and dose-response amperometry.

\section{Experimental}

Chemicals and reagents.-Ferriprotoporphyrin IX chloride (hemin) $(\sim 90 \%)$, synthetic graphite powder ( $<20$ micron), sulfuric acid (95-98\%), hydrogen peroxide (30\%), dichloromethane, hexane, manganese (II) chloride tetrahydrate (99\%), manganese (IV) oxide $(99 \%)$, sodium nitrate $(99 \%)$, sodium chloride $(99 \%)$, potassium dihydrogen phosphate. dipotassium hydrogen phosphate. potassium permanganate. isopropanol, methanol. diethylene triamine pentaacetic acid (DTPA), ethanol. 3-morpholinosydnonimine hydrochloride (SIN-1) and isoamyl nitrite were all purchased from SigmaAldrich (St. Louis, MO) and used as such. Nano-pure deionized water (specific resistance $>18.2 \mathrm{M} \Omega \mathrm{cm}$ ) was supplied by a Barnstead water purification system model D8961. Indium Tin Oxide (ITO) coated glass slides were from Delta Technologies, Ltd. All other chemicals were reagent grade and used as received.

Instruments. - The electrochemical analyses were performed using CHI-1030B multi-mode potentiostat system. Amperometry and cyclic voltammetry measurements were carried out using the above mentioned electrochemical workstation. $\mathrm{Ag} / \mathrm{AgCl}$ is used as the reference electrode and all potentials reported here are measured versus this reference. A platinum wire was used as the auxiliary electrode, and glassy carbon electrodes (GCEs) with cast graphene-hemin or manganese-modifed graphene-hemin material were used as working electrodes. UV-Visible absorbance spectra were recorded on Agilent 8453 spectrophotometer. An Accumet AB15 pH-meter was used for $\mathrm{pH}$ measurements. SEM and EDX analyses were carried out using Hitachi S-4500 Field Emission Gun Scanning Electron Microscope. X-Ray Photoelectron Spectroscopy (XPS) was performed using PHI Versaprobe 5000 Scanning spectrometer at a pressure $\sim 10^{-4}$ millibar in the vacuum chamber. Monochromatic Al $\mathrm{K} \alpha \mathrm{X}$-ray beam was applied in the survey scans as well as in high-resolution analyses, with an estimated area of $0.35 \mathrm{~mm}^{2}$. A pass energy of $93.9 \mathrm{eV}$ was selected for sample surveys (0-800 eV), and $11.75 \mathrm{eV}$ was chosen for highresolution C1s $(278-298 \mathrm{eV})$, whereas $23.5 \mathrm{eV}$ was used for $\mathrm{Fe} 2 \mathrm{p}$ and $\mathrm{Mn} 2 \mathrm{p}(630-740 \mathrm{eV})$.

Synthesis and preparation.-Graphene oxide preparation.-In this study, a modified method of Hummers and Offerman was used to prepare graphene oxide. ${ }^{47}$ This method is based on the oxidation of graphite flakes in strong acid. In a typical preparation, $30 \mathrm{~mL}$ of concentrated sulfuric acid was added drop-wise to the solid mixture of $0.5 \mathrm{~g}$ of graphite powder and $0.3 \mathrm{~g}$ of sodium nitrate in a $250 \mathrm{~mL}$ round bottom flask at $0^{\circ} \mathrm{C}$. The second step consists of slowly adding $2.0 \mathrm{~g}$ of solid potassium permanganate to the reaction vessel. The reaction mixture is continuously stirred for 1 hour at $60^{\circ} \mathrm{C}$. Then, deionized water $(130 \mathrm{~mL})$ is gradually added to the mixture with continuous stirring for 0.5 hour. Finally, a solution of hydrogen peroxide $(30 \%)$ is slowly added to the reaction flask until the gas evolution stops. The final product was centrifuged for 1 hour to remove water and the excess of oxidizing reagents. The residue is then washed repeatedly with hydrochloric acid solution ( $5 \%$ ) followed by washing several times using deionized water and tested for sulfate ions using $\mathrm{BaCl}_{2}$ reagent. When the washing solution shows no sulfate ions, the final product is dried overnight in an oven at $60^{\circ} \mathrm{C}$ to obtain the solid graphene oxide (GO).

Graphene Oxide- $\mathrm{MnO}_{2}$ /hemin composite.-The graphene oxide (GO) as prepared was then functionalized with $\mathrm{MnO}_{2}$ nanoparticles by oxidizing manganese ions in situ as reported by Wang. ${ }^{25}$
Briefly, GO (0.066 g) and $\mathrm{MnCl}_{2} \cdot 4 \mathrm{H}_{2} \mathrm{O}(0.270 \mathrm{~g})$ are dispersed in isopropyl alcohol $(50.0 \mathrm{~mL})$, with ultrasonication for 1 hour. The reaction mixture was heated to $\sim 80^{\circ} \mathrm{C}$ under reflux with vigorous stirring. $\mathrm{KMnO}_{4}(0.150 \mathrm{~g})$ is dissolved in $5.0 \mathrm{~mL}$ of deionized water and then added to the mixture above and refluxing was allowed to continue for one hour. The mixture was then allowed to cool to room temperature. Finally, the prepared graphene- $\mathrm{MnO}_{2}$ composite material was centrifuged, washed, and then dried in air at $60^{\circ} \mathrm{C}$ for at least 12 hours. Finally, hemin was incorporated by adding $5 \mathrm{mM}$ solution of iron protoporphyrin IX in $5.0 \mathrm{~mL}$ methanol to $5.0 \mathrm{mg}$ of graphene- $\mathrm{MnO}_{2}$ dispersed in $5.0 \mathrm{~mL}$ of deionized water and put under sonication. The sonication was continued for 5 hours, followed by centrifugation, and washing of the precipitate. The solid was then dried at $60^{\circ} \mathrm{C}$ to obtain the final composite of $\mathrm{GO}-\mathrm{MnO}_{2} /$ hemin. For comparison, we also prepared reduced graphene oxide/hemin (rGO/hemin) using the same method as reported in details in a previous work. $^{18}$

Peroxynitrite generation.-In this work, we used peroxynitrite released from 3-morpholinosydnonimine hydrochloride (SIN-1) at physiological $\mathrm{pH}$ as described earlier. ${ }^{18,48}$

Electrode modification.-Glassy carbon electrodes (GCEs) were polished on alumina pastes ( 0.3 and $0.05 \mu \mathrm{m}$ respectively) using a Buehler microcloth polishing disk, followed by sonication in a mixture of ethanol and acetone for 1 minute to remove any polishing residue, then flushed repeatedly with a deionized water. The electrodes are then modified by the drop-casting method. A suspension of GO- $\mathrm{MnO}_{2} /$ hemin or $\mathrm{rGO} /$ hemin composite was sonicated in methanol for 1 hour and then cast on the surface of GCE. The electrode is left for 30 minutes to dry. This process was repeated three times using a $10-\mu \mathrm{L}$ aliquot each time. Finally, the modified electrodes were washed several times with a deionized water and phosphate buffer solution $\mathrm{pH}=7.4$ before use in the electrochemical experiments.

\section{Results and Discussion}

Preparation and characterization.-A simple and direct method has been developed to prepare the composite $\mathrm{GO}-\mathrm{MnO}_{2} /$ hemin matrix. The process uses acid oxidation of graphite flakes using Hummers method to form the GO sheets. ${ }^{47}$ The GO obtained was mixed with manganese chloride salt and dispersed in isopropyl alcohol and subjected to ultrasonication. Oxidation was allowed by adding $\mathrm{KMnO}_{4}$ under reflux with stirring to obtain the composite $\mathrm{GO}-\mathrm{MnO}_{2}$ as described by Wang and Zhu. ${ }^{25}$

Hemin was then introduced to allow for $\pi-\pi$ stacking interaction under ultrasonication for few hours to form the final matrix of GO$\mathrm{MnO}_{2} /$ hemin. Scheme 1 illustrates the various preparation steps to form the first composite $\left(\mathrm{GO}-\mathrm{MnO}_{2}\right)$, followed by addition of hemin to form the reduced $\mathrm{GO} /$ hemin (rGO/hemin) and $\mathrm{GO}-\mathrm{MnO}_{2} /$ hemin composite materials.

SEM analysis was used to study the change in morphology and surface features of the functionalized grapheme-based composite materials. The SEM images of GO, $\mathrm{rGO} /$ hemin, $\mathrm{GO}-\mathrm{MnO}_{2}$, and GO$\mathrm{MnO}_{2} /$ hemin are shown in Figure 1. The characteristic micrograph images illustrate the reaction steps of the final product $\mathrm{GO}-\mathrm{MnO}_{2}$ /hemin nanocomposite. The solid powder of sample collected at different preparation steps were mounted and subjected for the SEM analyses. The SEM images show a random orientation of GO nanosheets in both GO and $\mathrm{rGO} /$ hemin samples, Figures $1 \mathrm{~A}$ and $1 \mathrm{~B}$. The SEM image of $\mathrm{GO}-\mathrm{MnO}_{2}$ shows needle-like structure of this composite nanomaterial, Figure $1 \mathrm{C}$. This is similar to findings by Wang and Zhu who described the formation of the needle-like manganese oxide crystals on graphene oxide sheets via a mechanism of intercalation and adsorption of manganese ions on graphene oxide sheets. Oxidation then triggers nucleation and oriented growth of needle-like $\mathrm{MnO}_{2}$ crystals on graphene oxide. ${ }^{25}$ The length of the nanoneedles in our preparation is in the $100-200 \mathrm{~nm}$ range, with $40-50 \mathrm{~nm}$ width. This is consistent with data reported earlier. ${ }^{24,25}$ Finally, the SEM of GO-MnO 2 /hemin 


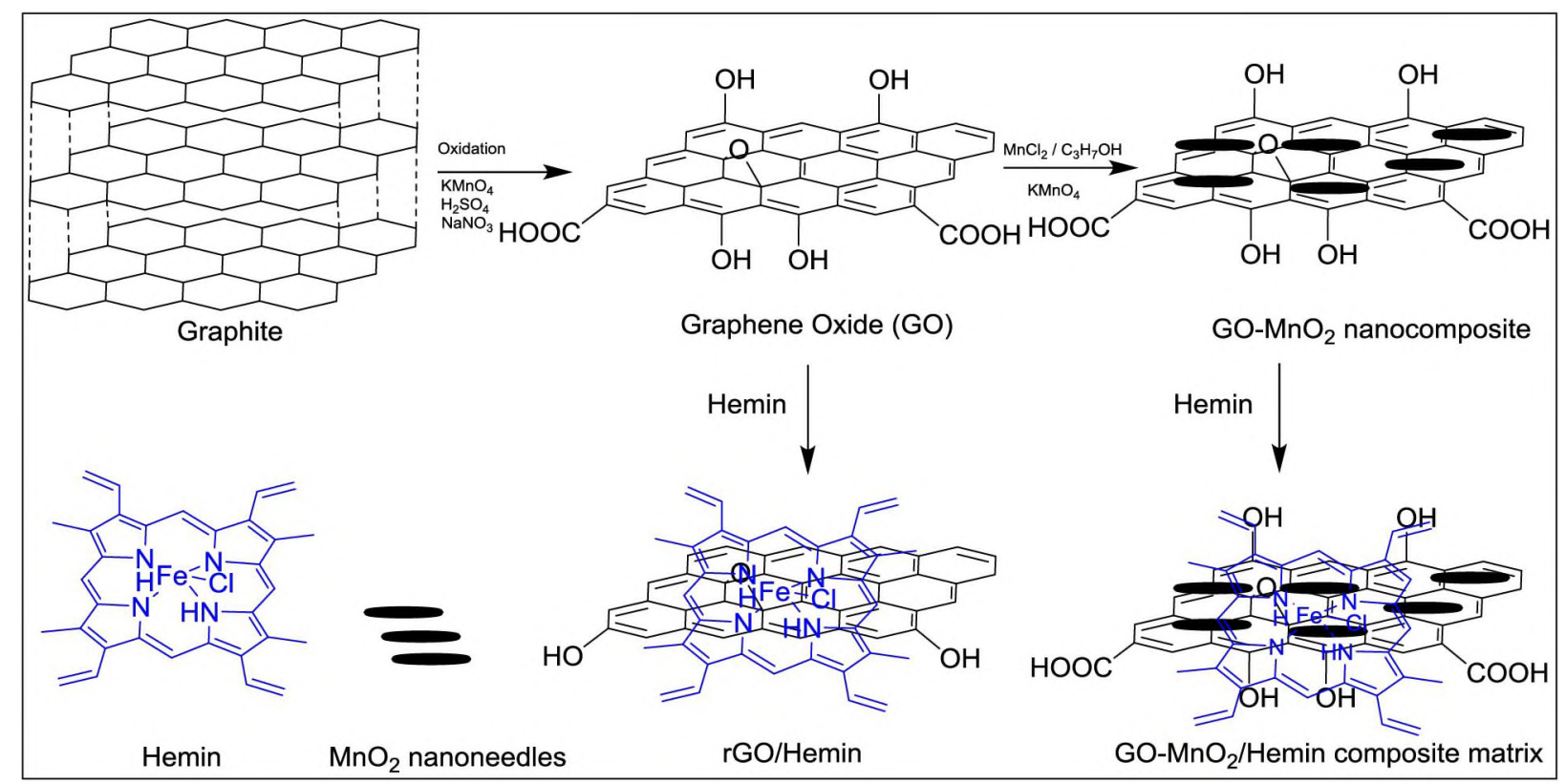

Scheme 1. Schematic representation of the preparation steps of GO, GO- $\mathrm{MnO}_{2}, \mathrm{rGO} /$ hemin and $\mathrm{GO}-\mathrm{MnO}_{2} /$ hemin composite materials.

nanocomposite also shows the morphological characteristics needlelike structures $\mathrm{GO}-\mathrm{MnO}_{2}$, Figure 1D.

We performed EDX elemental analysis of $\mathrm{GO}-\mathrm{MnO}_{2} /$ hemin sample and for comparison we also analyzed GO and $\mathrm{rGO} /$ hemin under the same conditions. Figure 2 . The relative atomic weight ratios for the various samples are listed in Table I. The carbon/oxygen $(\mathrm{C} / \mathrm{O})$ atomic ratio is indicative of the degree of graphene oxidation. and assesses the nature of oxygen functionalities. The degree of oxidation of the prepared graphene oxide can be estimated from $\mathrm{C} / \mathrm{O}$ ratio. Optimally oxidized graphene oxide $\mathrm{C} / \mathrm{O}$ atomic ratio lies between 2.1 to $2.9 .{ }^{47}$ The samples of GO prepared in this work exhibited a $\mathrm{C} / \mathrm{O}$ atomic ratio of 2.15 , consistent with the range reported for well-oxidized graphene.
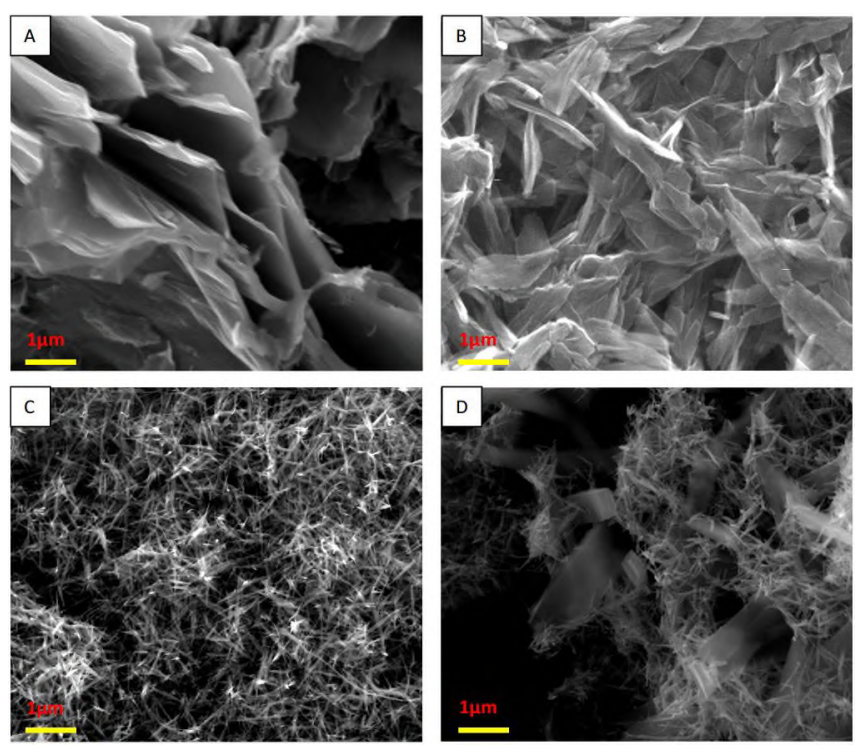

Figure 1. SEM images of sample collected at different preparation steps of graphene-based nanomaterials: (A) Graphene oxide (GO) as prepared using the modified Hummers' method, (B) reduced graphene oxide/hemin composite (rGO/hemin) using the method described earlier ${ }^{18}$ (C) Graphene-manganese oxide nanocomposite material $\mathrm{GO}-\mathrm{MnO}_{2}$, (D) $\mathrm{GO}-\mathrm{MnO}_{2}$ material after treatment with hemin as described above to yield $\mathrm{GO}-\mathrm{MnO}_{2} /$ hemin.
Another support for the optimal level of oxidation of the prepared GO comes from the yellowish color of the sample when it is dispersed in deionized water. ${ }^{47}$ The atomic weight ratio $\mathrm{C} / \mathrm{O}$ of $\mathrm{GO}$ increased from 2.15 to 2.8 after mixing with hemin under ultrasonication. This result is evidence for some degree of reduction of the graphene oxide sheets upon treatment with hemin. This confirms the role of hemin as a reducing agent, as reported earlier using the deconvolution of $\mathrm{Cls}$ in high-resolution XPS. ${ }^{18}$

In contrast, the $\mathrm{Mn}$-based material, $\mathrm{GO}-\mathrm{MnO}_{2} /$ hemin, has a very low value of $\mathrm{C} / \mathrm{O}$ atomic ratio, indicating more oxygen in the final composite product. The introduction of $\mathrm{MnO}_{2}$ nanoparticles obviously increases the relative amount of oxygen atoms and therefore the $\mathrm{C} / \mathrm{O}$ atomic weight ratio of the corresponding material is expected to decrease significantly.

Figure 2 also shows the difference between the EDX spectra of $\mathrm{rGO} /$ hemin and $\mathrm{GO}-\mathrm{MnO}_{2} /$ hemin in terms of iron and manganese peaks. As expected, a new peak of $\mathrm{Mn}$ appears in the case of GO$\mathrm{MnO}_{2}$ /hemin and is absent in $\mathrm{rGO} /$ hemin, consistent with the formation of GO- $\mathrm{MnO}_{2} /$ hemin nanocomposite. Also, the atomic weight percentage of iron increased from $1.75 \mathrm{in} \mathrm{rGO} /$ hemin to 2.87 atomic weight $\%$ in the final GO- $\mathrm{MnO}_{2} /$ hemin material. The oxidation of manganese ions in the water-isopropanol solvent system allows for the oriented growth of manganese oxide nanoneedles. This process was shown to cause further exfoliation of graphene oxide sheets. ${ }^{25}$ The manganese oxide-driven exfoliation of graphene oxide is expected to allow for more hemin intercalation within graphene sheets in GO$\mathrm{MnO}_{2} /$ hemin, which may explain the increase of the Fe peak in the EDX spectrum of this nanocomposite material. ${ }^{25}$

Table I. EDX Elemental Analysis of graphene oxide GO as prepared, and of GO after treatment with hemin (rGO/hemin) and of $\mathrm{GO}-\mathrm{MnO}_{2}$ after treatment with hemin (GO-MnO $\mathrm{H}_{2} / \mathrm{hemin}$ ).

\begin{tabular}{llll} 
Atom Weight Percentage (\%) & $\mathrm{GO}$ & $\mathrm{rGO} /$ hemin & $\mathrm{GO}-\mathrm{MnO}_{2} /$ hemin \\
\hline $\mathrm{C} \%$ & 68.13 & 70.78 & 30.40 \\
$\mathrm{O} \%$ & 31.70 & 25.32 & 41.73 \\
$\mathrm{Cl} \%$ & - & 2.15 & 0.59 \\
$\mathrm{Fe} \%$ & - & 1.75 & 2.87 \\
$\mathrm{Mn} \%$ & - & - & 24.41
\end{tabular}



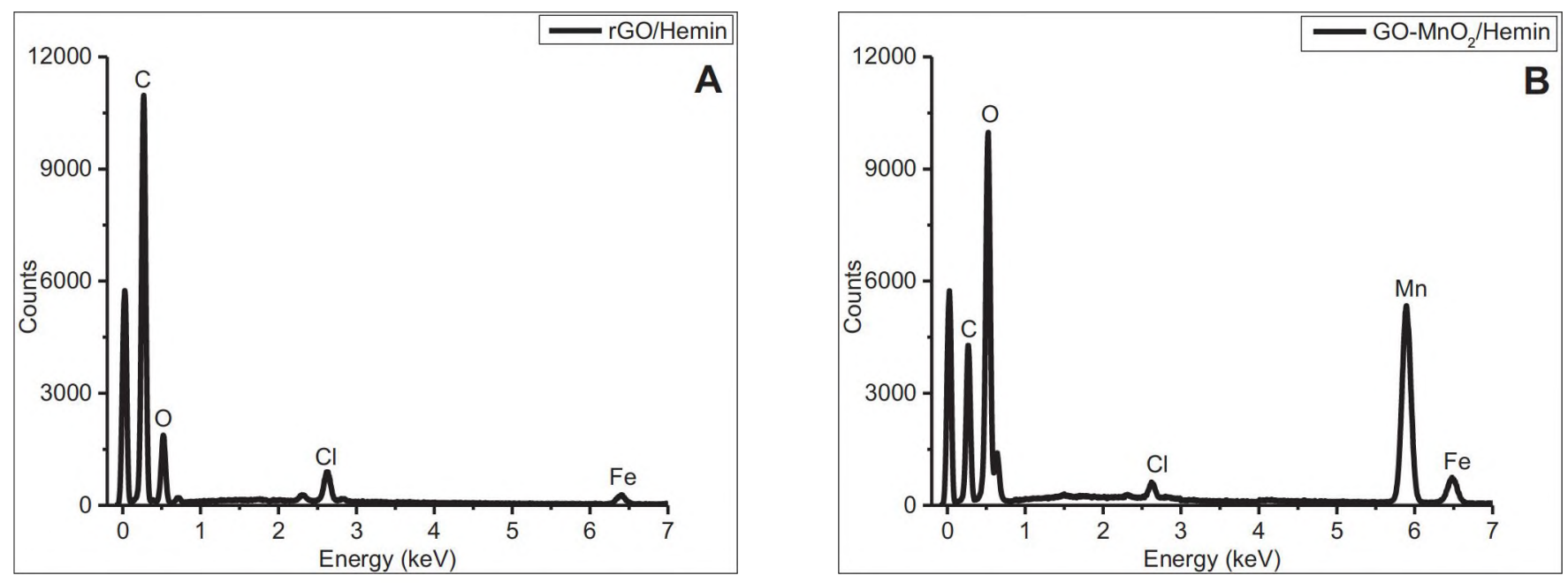

Figure 2. Energy Dispersive X-ray (EDX) spectra of graphene oxide-based composite nanomaterials prepared as described in the Experimental section. (A) EDX spectrum of $\mathrm{rGO} /$ hemin material, and (B) EDX spectrum of $\mathrm{GO}-\mathrm{MnO}_{2} /$ hemin.

We then carried out XPS analysis to characterize the modified surfaces, and to identify the chemical changes in the various nanocomposites. As shown in Figure 3, high-resolution spectra have been obtained for C1s. N1s, Ols, Fe2p. and Mn2p of rGO/hemin and $\mathrm{GO}-\mathrm{MnO}_{2}$ /hemin as prepared. Initially. survey spectra were acquired for the graphene-based composites on the conductive ITO glass coated with the material in question using the drop-casting method, Figure 3A. The conductive ITO glass is also conveniently used, when needed, as a supporting electrode material for electrochemical analysis of the same material subjected to XPS. The XPS spectrum of blank ITO slide was taken under the same conditions and subtracted from the analyzed samples to eliminate the ITO background contribution.

The deconvolution of the $\mathrm{C} 1 \mathrm{~s}$ spectrum is often used to measure the degree of oxidation or reduction that occurs on the GO sheets upon chemical changes. ${ }^{18}$ Specifically, the three deconvoluted peaks of $\mathrm{C} 1 \mathrm{~s}$ at binding energies of $284.8 \mathrm{eV}(\mathrm{C}-\mathrm{C} / \mathrm{C}-\mathrm{H}), 286.7 \mathrm{eV}(\mathrm{C}-$ $\mathrm{OH} / \mathrm{C}-\mathrm{N})$, and $289.1 \mathrm{eV}(\mathrm{C}=\mathrm{O})$ are used to determine the chemical environment (oxidation state) of the graphene-based structures. ${ }^{49,50}$ The reduction of GO by hemin results in a significant decrease of the level of oxygen-bound carbons $(\mathrm{C}-\mathrm{OH} / \mathrm{C}=\mathrm{O})$, with concomitant increase in the amount of $\mathrm{sp}^{2}$ carbon hybridization. ${ }^{18}$ In the case of $\mathrm{rGO} /$ hemin versus $\mathrm{GO}-\mathrm{MnO}_{2} /$ hemin, we observe an overall decrease in the intensity of $\mathrm{sp}^{2} / \mathrm{C}-\mathrm{C}$ peaks in the presence of $\mathrm{MnO}_{2}$ particles, which seems to indicate that the introduction of $\mathrm{MnO}_{2}$ nanoparticles prevents hemin from reducing GO at the level observed in plain $\mathrm{rGO} /$ hemin. The high-resolution XPS spectra of $\mathrm{Cls}$ and N1s have almost the same binding energies at 283.8 and $397.6 \mathrm{eV}$. respectively. for $\mathrm{rGO} /$ hemin and $\mathrm{GO}-\mathrm{MnO}_{2} /$ hemin, indicating similar chemical states for both composites with respect to carbon and nitrogen contributions, Figures $3 \mathrm{C}$ and $3 \mathrm{D}$. The intensities of both $\mathrm{C} 1 \mathrm{~s}$ and $\mathrm{N} 1 \mathrm{~s}$ peaks of $\mathrm{rGO} /$ hemin are higher than the GO- $\mathrm{MnO}_{2} /$ hemin nanocomposite due to the predominant graphene and protoporphyrin moieties compared to the manganese-oxide nanoparticles in the final matrix. Interestingly, the $\mathrm{O} 1 \mathrm{~s}$ peak of the $\mathrm{GO}-\mathrm{MnO}_{2}$ /hemin matrix shows higher intensity and a slight negative chemical shift in binding energy compared to $\mathrm{rGO} / \mathrm{hemin}$ (compare $530.0 \mathrm{eV}$ to $531.8 \mathrm{eV}$ ). Figure $3 \mathrm{~B}$. This negative shift suggests that there is more contribution of oxygen as $\mathrm{C}=\mathrm{O}$ or $\mathrm{HO}-\mathrm{C}=\mathrm{O}$ moieties in $\mathrm{GO}-\mathrm{MnO}_{2} /$ hemin compared to rGO/hemin. ${ }^{49}$ This conclusion is also supported by the careful analysis of the $\mathrm{C} 1 \mathrm{~s}$ spectra of $\mathrm{GO}-\mathrm{MnO}_{2}$ /hemin. which shows small peaks at 288,291 , and $293.5 \mathrm{eV}$, assigned to $\mathrm{C}=\mathrm{O} / \mathrm{HO}-\mathrm{C}=\mathrm{O}$ groups and $\pi-\pi$ conjugation, respectively. Together, these observations further support the conclusion that the incorporation of $\mathrm{MnO}_{2}$ nanoparticles seems to prevent hemin molecules from reducing GO sheets to the level observed in $\mathrm{rGO} /$ hemin samples.
As expected, $\mathrm{GO}-\mathrm{MnO}_{2}$ /hemin features characteristic XPS peaks of manganese, which is absent in $\mathrm{rGO}$ /hemin samples, Figure 3F. The $\mathrm{Mn} 2 \mathrm{p}$ spectrum of GO- $\mathrm{MnO}_{2} /$ hemin exhibits two peaks for $2 \mathrm{p}_{3 / 2}$ and $2 p_{1 / 2}$ chemical states at 642 and $653 \mathrm{eV}$ respectively, with binding energy difference of $11 \mathrm{eV}$ as reported in the literature. ${ }^{51}$

The incorporation of hemin in the prepared composites is confirmed by the presence of the iron peaks. The two materials exhibit the same binding energy for the iron peak, which confirms similar chemical state of iron in both composites. Figure 3E. The spin-orbital coupling of $\mathrm{Fe} 2 \mathrm{p}_{3 / 2}$ and $\mathrm{Fe} 2 \mathrm{p}_{1 / 2}$ for both composites appears at binding energies of 712 and $725 \mathrm{eV}$, which is consistent with published data elsewhere. ${ }^{52}$ Interestingly, the $\mathrm{rGO}$ /hemin and $\mathrm{GO}-\mathrm{MnO}_{2}$ /hemin composites both have similar iron peak intensities in XPS. However, in EDX, analysis shows a relative increase in the iron peak in GO- $\mathrm{MnO}_{2}$ /hemin compared to $\mathrm{rGO} /$ hemin. The EDX info depth is $>500 \mathrm{~nm}$ compared to only $1-5 \mathrm{~nm}$ surface penetration in XPS analysis. The deeper sampling of EDX explains why this method better reflects the relative $\mathrm{Fe} \%$ in the $\mathrm{GO}-\mathrm{MnO}_{2}$ /hemin composite compared to $\mathrm{rGO} / \mathrm{hemin}$. The higher Fe content -and thus hemin contentin GO- $\mathrm{MnO}_{2}$ /hemin compared to $\mathrm{rGO} /$ hemin is consistent with the finding earlier that the oriented growth of needle-like crystals of $\mathrm{MnO}_{2}$ on graphene oxide leads to the exfoliation of GO sheets, and thus a relatively higher surface area for hemin intercalation.

We used UV/Vis analysis to investigate the formation of GO$\mathrm{MnO}_{2}$ and $\mathrm{GO}-\mathrm{MnO}_{2}$ /hemin nanocomposites as shown in Figure 4. In addition, UV/Vis absorption analysis of the initial components (starting materials) GO and hemin was conducted for comparison. A dispersed sample of $\mathrm{GO}$ and $\mathrm{GO}-\mathrm{MnO}_{2}$ nanomaterials in water were analyzed to monitor the composite formation and the observed changes in GO.

As observed in Figure 4A, the UV/Vis spectrum of GO suspension shows a maximum absorption at $228 \mathrm{~nm}$, which is ascribed to the $\pi-\pi^{*}$ transitions of the carbon in GO layers. In addition, a small shoulder is observed at $298 \mathrm{~nm}$ that is attributed to $n-\pi^{*}$ transitions of $\mathrm{C}=\mathrm{O}$ functionalities. Interestingly, the $\mathrm{GO}-\mathrm{MnO}_{2}$ nanocomposite exhibits also two predominant absorption peaks at $219 \mathrm{~nm}$ and $430 \mathrm{~nm}$ corresponding to $\mathrm{GO}$ ( $\pi-\pi^{*}$ transitions) and $\mathrm{MnO}_{2}$ (d-d transitions). respectively. The blue-shift of the graphene peak is attributed to the exfoliation of graphene sheets by $\mathrm{MnO}_{2}$ nanoneedles as reported by Wang et al. ${ }^{25}$ They reported blue-shift for the graphene peak and a concomitant red-shift for the $\mathrm{d}-\mathrm{d}$ of $\mathrm{Mn}$ as the reaction of formation of GO- $\mathrm{MnO}_{2}$ proceeds. Increasing the time of reaction causes the peak of $\mathrm{MnO}_{2}$ to gradually shift from 413 to $436 \mathrm{~nm}$, while the GO peak shifts from 230 to $216 \mathrm{~nm}^{25}$

The UV/Vis absorbance spectra of GO, GO- $\mathrm{MnO}_{2}$, hemin, and $\mathrm{GO}-\mathrm{MnO}_{2}$ /hemin are shown in Figure 4. The absorption 

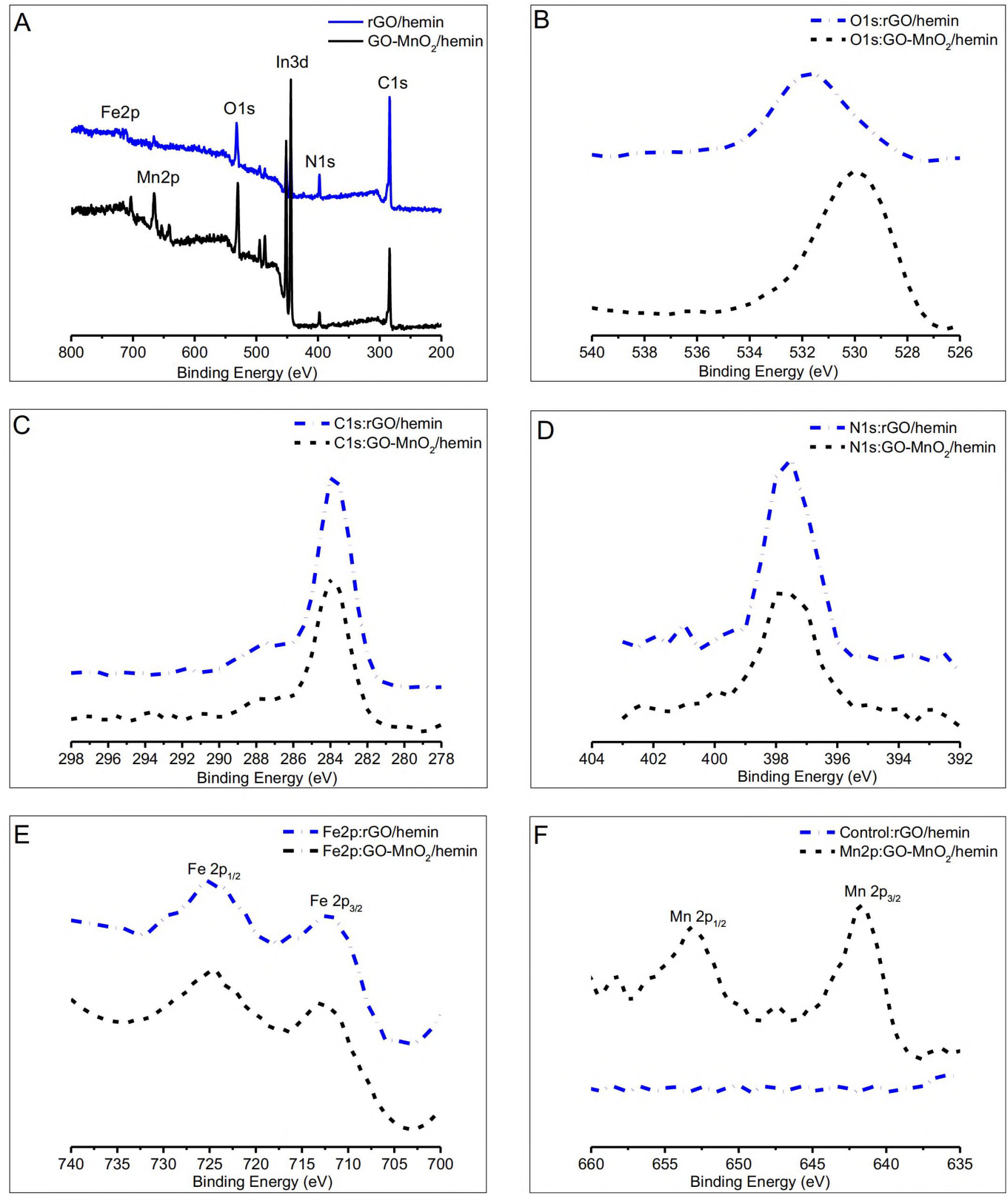

Figure 3. Survey and High-Resolution XPS analyses of rGO/hemin (blue) and $\mathrm{GO}-\mathrm{MnO}_{2}$ /hemin (black) samples: (A) XPS survey of the rGO/hemin and GO- $\mathrm{MnO}_{2} /$ hemin samples cast on ITO slide. Background contribution of ITO was subtracted using spectra acquired with non-coated ITO slides as blanks as described in the text (B) Ols High Resolution XPS spectra of $\mathrm{rGO} / \mathrm{hemin}$ and $\mathrm{GO}-\mathrm{MnO}_{2} /$ hemin samples, (C) C1s High Resolution XPS spectra of rGO/hemin and GO-MnO 2 /hemin, (D) N1s High Resolution XPS spectra of $\mathrm{rGO} / \mathrm{hemin}$ and $\mathrm{GO}-\mathrm{MnO}_{2} /$ hemin, (E) Fe2p High Resolution XPS spectra of rGO/hemin and GO- $\mathrm{MnO}_{2} /$ hemin samples, (F) Mn2p High Resolution XPS spectra of $\mathrm{rGO} /$ hemin and $\mathrm{GO}-\mathrm{MnO}_{2} /$ hemin samples under the same conditions. 


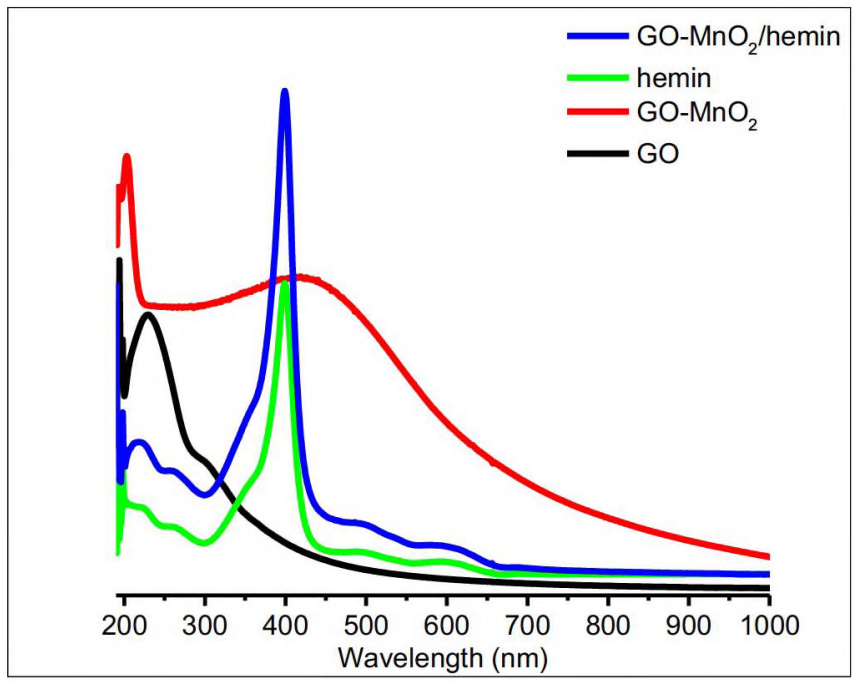

Figure 4. Characterization of $\mathrm{GO}-\mathrm{MnO}_{2} /$ hemin nanocomposite. UV/Vis spectra of (A) $\mathrm{GO}$ and $\mathrm{GO}-\mathrm{MnO}_{2}$ dispersed in water; (B) collection spectra of $\mathrm{GO}$, hemin. $\mathrm{GO}-\mathrm{MnO}_{2}$ and $\mathrm{GO}-\mathrm{MnO}_{2} /$ hemin composite in methanol.

characteristics of the $\mathrm{GO}-\mathrm{MnO}_{2}$ /hemin nanocomposite suspended in water shows the Soret absorption band of incorporated hemin, as well as the peak of GO. For comparison, absorption characteristics of hemin in solution confirms that the absorption at approximately the same wavelength $(\sim 400 \mathrm{~nm})$ is that of hemin intercalated within the GO sheets. The incorporation of hemin in the graphene-manganese composite is also indicated by the presence of weak peaks between $420 \mathrm{~nm}$ to $640 \mathrm{~nm}$ corresponding to the hemin Q-bands. ${ }^{18,36}$ Together, these spectroscopic data show that the hemin rings are incorporated as monomeric entities within the $\mathrm{GO}-\mathrm{MnO}_{2}$ nanomaterial.

The relatively weak $\mathrm{d}$-d transition peak of $\mathrm{MnO}_{2}$ is obscured by the intense hemin Soret-band in the final matrix nanocomposite; however. a careful observation still shows the broad shoulder at $430 \mathrm{~nm}$ for the $\mathrm{GO}-\mathrm{MnO}_{2}$ /hemin final material.

In conclusion, EDX, XPS, and UV/Vis analyses of the GO$\mathrm{MnO}_{2}$ /hemin material show the general features of all matrix components, and together confirm the formation of the target nanocomposite material. We next use this prepared material on electrode surfaces to test its activity in catalytic sensing of peroxynitrite.

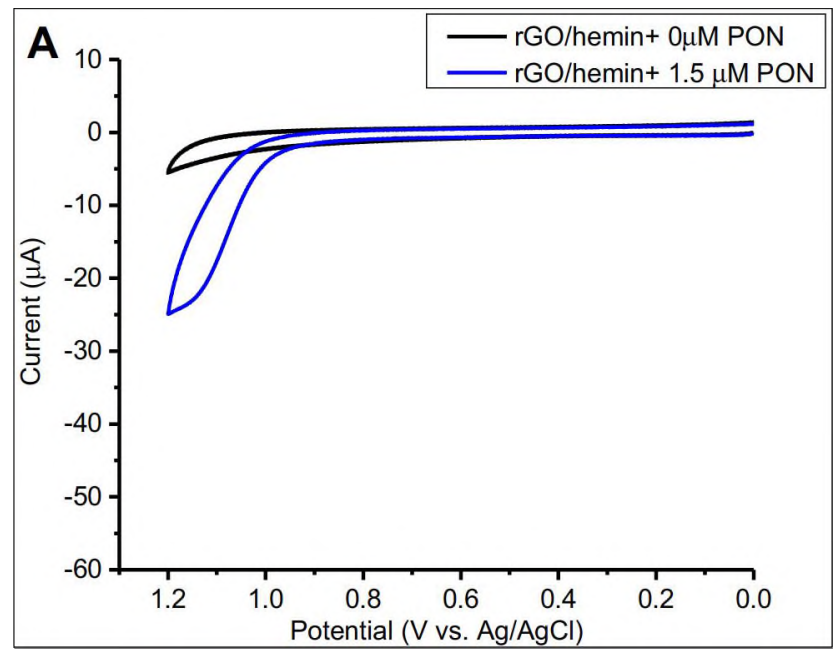

Electrochemical measurements and sensor performance.The electrochemical performance of the $\mathrm{rGO} / \mathrm{hemin}$ and GO$\mathrm{MnO}_{2}$ /hemin-modified GCEs was examined side-by-side using cyclic voltammetry analysis in phosphate buffer. The brown-red suspension of $\mathrm{rGO} /$ hemin and the brown-black suspension of $\mathrm{GO}-\mathrm{MnO}_{2} /$ hemin were drop-cast on freshly polished glassy carbon electrodes (GCEs) and allowed to dry before use as described in detail in the Experimental section. The typical voltammetric response in absence and presence of peroxynitrite (PON) is shown in Figure 5. We used SIN-1 as a peroxynitrite generator in situ at physiological $\mathrm{pH}$. In the presence of PON, the $\mathrm{rGO} /$ hemin voltammogram shows an oxidative peak response at $\sim+1.1 \mathrm{~V}$ attributed to the catalytic oxidation of PON mediated by hemin on graphene. The mechanism of the catalytic activity of heminmediated peroxynitrite oxidation has been previously reported. ${ }^{18.41} \mathrm{~A}$ similar mechanism is proposed for $\mathrm{GO}-\mathrm{MnO}_{2}$ /hemin and is shown in Scheme 2.

The incorporation of $\mathrm{MnO}_{2}$ in the graphene/hemin composite shifts the catalytic oxidation peak of peroxynitrite to a lower peak potential by about $200 \mathrm{mV}$. As a result, a well-defined peak for the catalytic oxidation appears at approximately $+0.9 \mathrm{~V}$ vs. $\mathrm{Ag} / \mathrm{AgCl}$ as shown in Figure $5 \mathrm{~B}$. The shift of the catalytic peak to less positive potentials indicates that the incorporation of $\mathrm{MnO}_{2}$ particles on $\mathrm{GO} /$ hemin nanocomposite helps lower the barrier of mediated electrochemical oxidation of PON at the modified interface. Also, as we established earlier, the added exfoliation of $\mathrm{GO}$ enabled by the needle-like $\mathrm{MnO}_{2}$ nanoparticles allows for the incorporation of more hemin catalyst in the nanocomposite material. Both effects result in higher current response at less positive potential.

Amperometric measurements have been used to compare and contrast the electrocatalytic activity and the performance of the various composite materials. Again, we used nanomolar-range aliquots of PON released from $1 \mu \mathrm{M}$ stock solution of SIN-1.

The amperometric response of the modified electrodes to added PON aliquots was measured after each injection for sensors with GO$\mathrm{MnO}_{2} /$ hemin as well as with $\mathrm{rGO} /$ hemin for comparison. The applied potential in both cases was of $+1 \mathrm{~V}$ vs. $\mathrm{Ag} / \mathrm{AgCl}$.

Figure $6 \mathrm{~A}$ shows the typical current responses associated with the addition of PON aliquots to the electrochemical cell in phosphate buffer at $\mathrm{pH}$ 7.4. As expected based on cyclic voltammetry, we observe a significantly larger response in catalytic oxidation current of PON on electrodes modified with $\mathrm{GO}-\mathrm{MnO}_{2} /$ hemin as compared to electrodes modified with rGO/hemin. Calibration curves based on amperometry show linear correlation between measured currents and added PON concentration in the range of 2.0 to $10.0 \mathrm{nM}$ for both

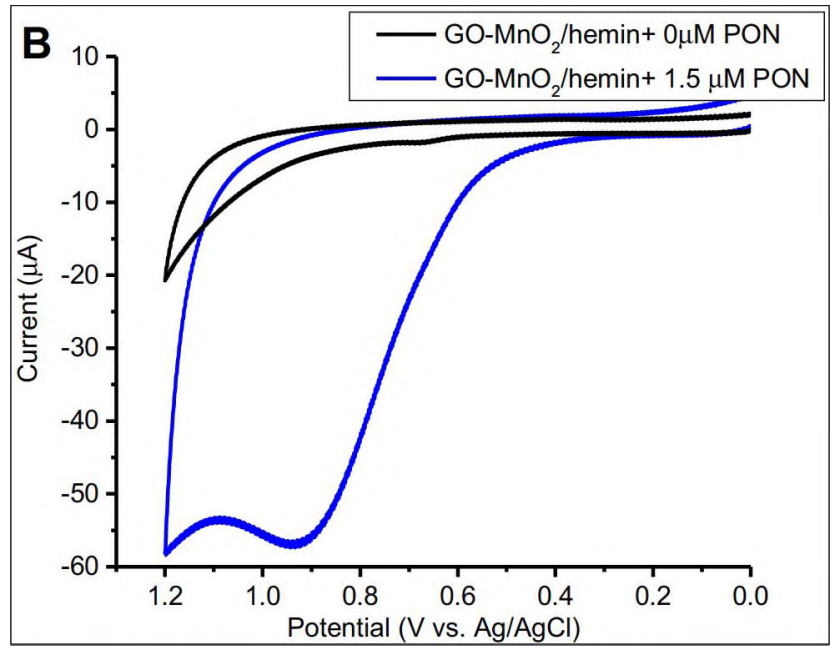

Figure 5. Cyclic voltammetry responses of GCEs modified with $\mathrm{rGO} /$ hemin and $\mathrm{GO}-\mathrm{MnO}_{2} /$ hemin in absence and presence of PON released in situ from SIN-1 in PBS $\mathrm{pH}=7.4$. The scan rate is $0.1 \mathrm{v} / \mathrm{sec}$ for all voltammograms: (A) Voltammetric response of $\mathrm{rGO} / \mathrm{hemin}$ in absence and presence of $1.5 \mathrm{uM}$ PON, (B) Voltammeric response of $\mathrm{GO}-\mathrm{MnO}_{2} /$ hemin absence and presence of $1.5 \mathrm{uM} \mathrm{PON}$. 


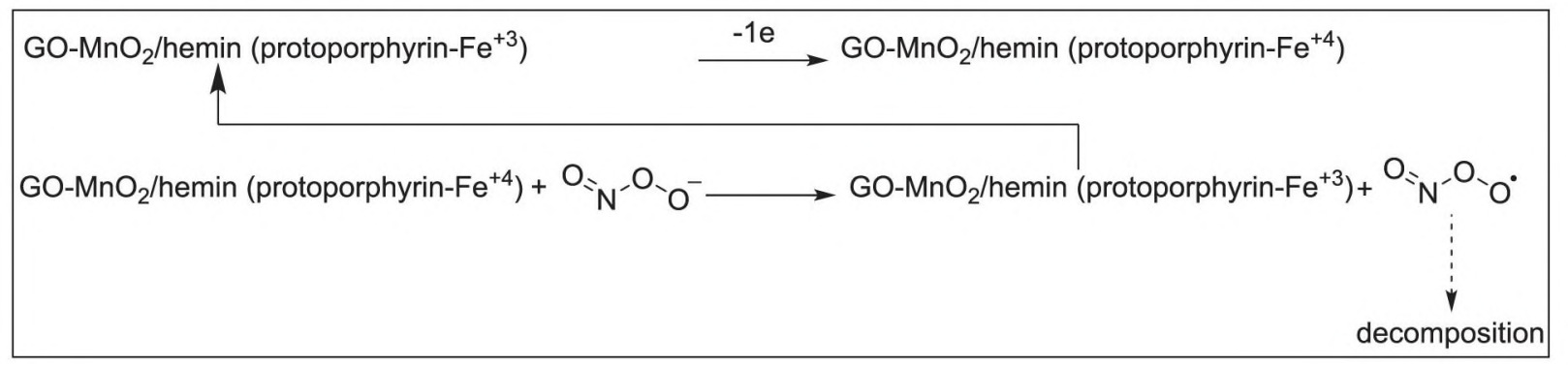

Scheme 2. Proposed catalytic oxidation of peroxynitrite on $\mathrm{GO}-\mathrm{MnO}_{2} /$ hemin composite interface on GCE.
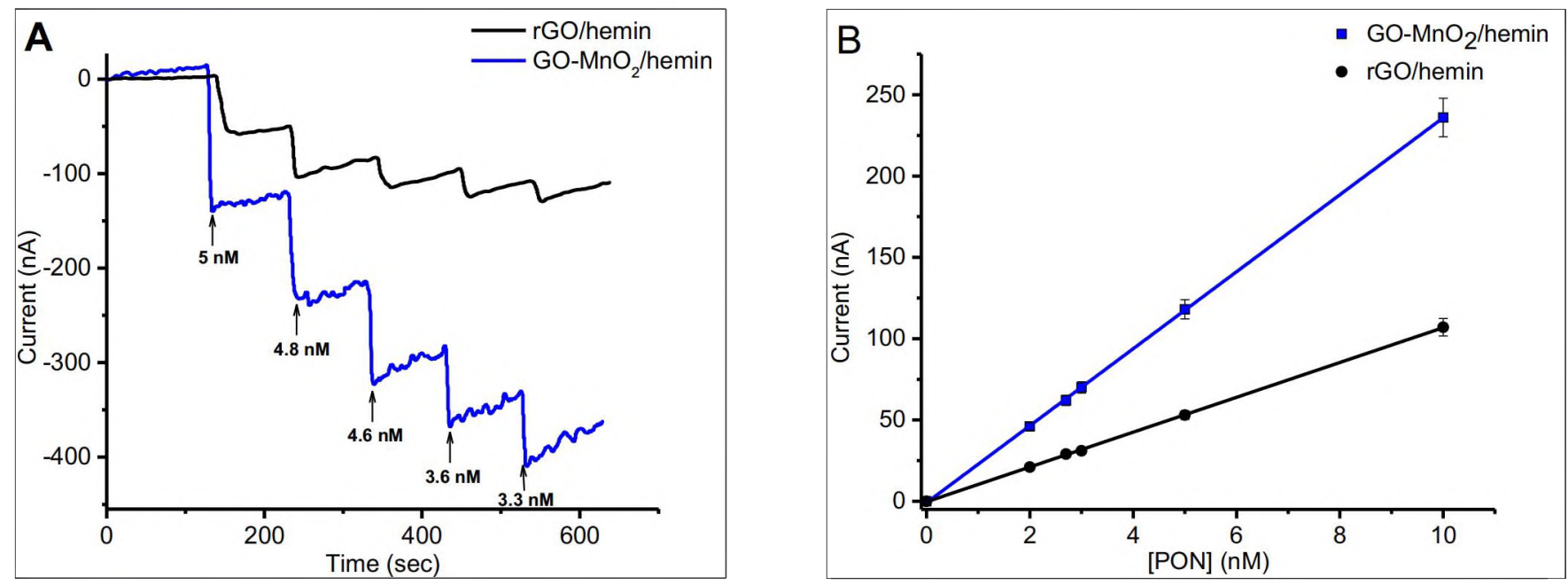

Figure 6. (A) Typical amperometric responses of glassy carbon electrodes modified with rGO/hemin and GO-MnO $\mathrm{O}_{2}$ /hemin after consecutive additions of nanomolar PON aliquots released from SIN-1 solution in PBS pH $=7.4$. The applied potential is $+1 \mathrm{~V} \mathrm{vs.} \mathrm{Ag/AgCl} \mathrm{for} \mathrm{all} \mathrm{cases} \mathrm{(B)} \mathrm{The} \mathrm{calibration} \mathrm{curves} \mathrm{of}$ current versus added $\mathrm{PON}$ concentration for $\mathrm{rGO} /$ hemin and $\mathrm{GO}-\mathrm{MnO}_{2}$ /hemin sensors based on the amperometric current responses observed in (A).

systems. Linear regression analyses show a sensitivity of $23.7 \mathrm{nA} / \mathrm{nM}$ for $\mathrm{GO}-\mathrm{MnO}_{2} /$ hemin as opposed to only $\sim 10 \mathrm{nA} / \mathrm{nM}$ for $\mathrm{rGO} / \mathrm{hemin}$. The relative detection limit of the $\mathrm{GO}-\mathrm{MnO}_{2}$ /hemin-modified sensors was $2.0 \mathrm{nM}$ with overall good sensor stability.

\section{Conclusions}

We have described a preparation method of sensors with a nanomaterial based on hemin- and $\mathrm{MnO}_{2}$-functionalized graphene oxide nanosheets. Glassy carbon electrode sensors with the prepared nanocomposite material showed relatively higher catalytic activity for peroxynitrite detection in phosphate buffer at $\mathrm{pH}$ 7.4. This work highlights for the first time the effect of $\mathrm{MnO}_{2}$ incorporation in $\mathrm{GO} /$ hemin on carbon-based sensors toward the electrocatalytic detection of PON. The incorporation of $\mathrm{MnO}_{2}$ nanoparticles not only allows for more adsorbed hemin entities into the final composite matrix, but also lowers the barrier of mediated electrochemical oxidation of PON. As a result, amperometric calibration curves of the $\mathrm{GO}-\mathrm{MnO}_{2} /$ hemin-modified sensors show a significant increase in sensitivity toward peroxynitrite detection in physiological $\mathrm{pH}$ compared to rGO/hemin sensors. We are now adapting the same catalytic interface (GO- $\mathrm{MnO}_{2} /$ hemin) on a miniaturize platform consisting of carbon fiber electrodes in order to test their use as sensors for peroxynitrite at the level of single cells or collection of cells.

\section{Acknowledgment}

This work was supported by National Institutes of Health grant EB019739 to M.B. M.B and H.K. recognize a DRA award from the Office of Sponsored programs of Cleveland State University. We thank
Ousama K. Al-Mahmoud and Clara L. Kay for initial assistance with some aspects of this work.

\section{ORCID}

Mekki Bayachou 9 https://orcid.org/0000-0002-0231-923X

\section{References}

1. P. Pacher, L. Liaudet. P. Bai, J. G. Mabley, P. M. Kaminski, L. Virag. A. Deb, E. Szabo, Z. Ungvari, M. S. Wolin, J. T. Groves, and C. Szabo, "Potent Metalloporphyrin Peroxynitrite Decomposition Catalyst Protects against the Development of Doxorubicin-Induced Cardiac Dysfunction." Circulation, 107(6), 896 (2003).

2. S. Levrand, B. Pesse, F. Feihl, B. Waeber, P. Pacher, J. Rolli, M. D. Schaller, and L. Liaudet, "Peroxynitrite Is a Potent Inhibitor of Nf- $\{$ Kappa $\}$ B Activation Triggered by Inflammatory Stimuli in Cardiac and Endothelial Cell Lines." The Journal of biological chemistry, 280(41), 34878 (2005).

3. B. Pesse, S. Levrand, F. Feihł, B. Waeber, B. Gavillet, P. Pacher, and L. Liaudet, "Peroxynitrite Activates Erk Via Raf-1 and Mek, Independently from Egf Receptor and P2I ras in H9c2 Cardiomyocytes," Joumal of molecular and cellular cardiology, 38(5), 765 (2005).

4. S. Levrand, C. Vannay-Bouchiche, B. Pesse, P. Pacher, F. Feihl, B. Waeber, and L. Liaudet, "Peroxynitrite Is a Major Trigger of Cardiomyocyte Apoptosis in Vitro and in Vivo." Free Radic Biol Med, 41(6), 886 (2006).

5. P. Pacher and C. Szabo, "Role of Peroxynitrite in the Pathogenesis of Cardiovascular Complications of Diabetes." Curr Opin Pharmacol, 6(2), 136 (2006).

6. S. Levrand, P. Pacher, B. Pesse, J. Rolli, F. Feihl, B. Waeber, and L. Liaudet, "Homocysteine Induces Cell Death in H9c2 Cardiomyocytes through the Generation of Peroxynitrite." Biochem Biophys Res Commun, 359(3), 445 (2007).

7. N. Loukili, N. Rosenblatt-Velin, J. Li, S. Clere, P. Pacher, F. Feihl, B. Waeber, and L. Liaudet, "Peroxynitrite Induces Hmgb1 Release by Cardiac Cells in Vitro and Hmgbl Upregulation in the Infarcted Myocardium in Vivo." Cardiovasc Res, 89(3), $586(2011)$,

8. J. Li, N. Loukili, N. Rosenblatt-Velin, P. Pacher, F. Feihl, B. Waeber, and L. Liaudet, "Peroxynitrite Is a Key Mediator of the Cardioprotection Afforded by Ischemic Postconditioning in Vivo." PLoS One, 8(7), e70331 (2013). 
9. P. Pacher, I. G. Obrosova, J. G. Mabley, and C. Szabo, "Role of Nitrosative Stress and Peroxynitrite in the Pathogenesis of Diabetic Complications. Emerging New Therapeutical Strategies." Curr Med Chem, 12(3), 267 (2005).

10. P. Pacher, J. S. Beckman, and L. Liaudet, "Nitric Oxide and Peroxynitrite in Health and Disease." Physiol Rev, 87(1), 315 (2007).

11. P. Mukhopadhyay, M. Rajesh, S. Batkai, Y. Kashiwaya, G. Hasko, L. Liaudet, C. Szabo, and P. Pacher, "Role of Superoxide, Nitric Oxide, and Peroxynitrite in Doxorubicin-Induced Cell Death in Vivo and in Vitro." Am J Physiol Heart Circ Physiol, 296(5), H1466 (2009).

12. C Szabo, J G. Mabley, S. M Moeller, R Shimanovich, P Pacher, L. Virag, F. G. Soriano, J. H. Van Duzer, W. Williams, A. L. Salzman, and J. T. Groves, "Part I Pathogenetic Role of Peroxynitrite in the Development of Diabetes and Diabetic Vascular Complications: Studies with Fp15, a Novel Potent Peroxynitrite Decomposition Catalyst." Mol Med, 8(10), 571 (2002).

13. J. G. Mabley, L. Liaudet, P. Pacher, G. J. Southan, J. T. Groves, A. L. Salzman, and C. Szabo, "Part II: Beneficial Effects of the Peroxynitrite Decomposition Catalyst Fp15 in Murine Models of Arthritis and Colitis." Mol Med, 8(10), 581 (2002).

14. P. Pacher and C. Szabo, "Role of the Peroxynitrite-Poly(Adp-Ribose) Polymerase Pathway in Human Disease." Am J Pathol, 173(1), 2 (2008).

15. L. Liaudet, G. Vassalli, and P. Pacher, "Role of Peroxynitrite in the Redox Regulation of Cell Signal Transduction Pathways." Front Biosci (Landmark Ed), 14, 4809 (2009).

16. V. R. Drel. P. Pacher, I. Vareniuk, I. A. Pavlov, O. Ilnytska, V. V. Lyzogubov, S. R. Bell, J. T. Groves, and I. G. Obrosova, "Evaluation of the Peroxynitrite Decomposition Catalyst Fe(Iii) Tetra-Mesitylporphyrin Octasulfonate on Periphera Neuropathy in a Mouse Model of Type 1 Diabetes." Int J Mol Med, 20(6), 783 (2007).

17. Y. Wang and Z. Z. Chen, "A Novel Poly(Cyanocobalamin) Modified Glassy Carbon Electrode as Electrochemical Sensor for Voltammetric Determination of Peroxynitrite." Talanta, 82(2), 534 (2010).

18. R. Oprea, S. F. Peteu, P. Subramanian, W. Oi. E. Pichonat, H. Happy, M. Bayachou, R. Boukherroub, and S. Szunerits, "Peroxynitrite Activity of Hemin-Functionalized Reduced Graphene Oxide." Analyst, 138(15), 4345 (2013).

19. S. F. Peteu, R. Boukherroub, and S. Szunerits, "Nitro-Oxidative Species in Vivo Biosensing: Challenges and Advances with Focus on Peroxynitrite Quantification." Biosens Bioelectron, 58, 359 (2014).

20. D. Li, M. B. Muller, S. Gilje, R. B. Kaner, and G. G. Wallace, "Processable Aqueous Dispersions of Graphene Nanosheets." Nat Nanotechnol, 3(2), 101 (2008)

21. G. Zhu, Y. Liu, Z. Xu, T. Jiang, C. Zhang, X. Li, and G. Qi, "Flexible Magnetic Nanoparticles-Reduced Graphene Oxide Composite Membranes Formed by SelfAssembly in Solution." Chemphyschem, 11(11), 2432 (2010).

22. Y. Zhu, S. Murali, W. Cai, X. Li, J. W. Suk, J. R. Potts, and R. S. Ruoff, "Graphene and Graphene Oxide: Synthesis, Properties, and Applications." Adv Mater, 22(35), $3906(2010)$.

23. L. W. Chen, C. M. Hsu, J. S. Wang, J. S. Chen, and S. C. Chen, "Specific Inhibition of Inos Decreases the Intestinal Mucosal Peroxynitrite Level and Improves the Barrier Function after Thermal Injury." Burns, 24(8), 699 (1998).

24. S. Chen, J. Zhu, and X. Wang, "From Graphene to Metal Oxide Nanolamellas: A Phenomenon of Morphology Transmission." ACS Nano, 4(10), 6212 (2010).

25. S. Chen, J. Zhu, X. Wu, Q. Han, and X. Wang, "Graphene Oxide-Mno2 Nanocomposites for Supercapacitors." ACS Nano, 4(5), 2822 (2010).

26. Z. Tang, S. Shen, J. Zhuang, and X. Wang, "Noble-Metal-Promoted ThreeDimensional Macroassembly of Single-Layered Graphene Oxide." Angew Chem Int Ed Engl, 49(27), 4603 (2010).

27. J. Zhu, G. Zeng, F. Nie, X. Xu, S. Chen, Q. Han, and X. Wang, "Decorating Graphene Oxide with Cuo Nanoparticles in a Water-Isopropanol System." Nanoscale, 2(6), 988 (2010)

28. Z. H. Xue, B. Yin, H. Wang, M. Q. Li, H. H. Rao, X. H. Liu, X. B. Zhoua, and X. Q. Lu, "An Organic Indicator Functionalized Graphene Oxide NanocompositeBased Colorimetric Assay for the Detection of Sarcosine." Nanoscale, 8(10), 5488 (2016).

29. Q. Tu, C. Tian, T. Ma, L. Pang, and J. Wang, "Click Synthesis of Quaternized Poly(Dimethylaminoethyl Methacrylate) Functionalized Graphene Oxide with Improved Antibacterial and Antifouling Ability." Colloids Surf B Biointerfaces, 141. $196(2016)$.

30. Z. Zeng, D. Yu, Z. He, J. Liu, F. X. Xiao, Y. Zhang, R. Wang, D. Bhattacharyya, and T. T. Tan, "Graphene Oxide Quantum Dots Covalently Functionalized Pvdf Membrane with Significantly-Enhanced Bactericidal and Antibiofouling Performances." Sci Rep, 6, 20142 (2016)

31. N. Wang, M. Lin, H. Dai, and H. Ma, "Functionalized Gold Nanoparticles/Reduced Graphene Oxide Nanocomposites for Ultrasensitive Electrochemical Sensing of Mercury Ions Based on Thymine-Mercury-Thymine Structure." Biosens Bioelectron, 79, 320 (2016)
32. X. Zhu, Y. Cui, X. Chang, and H. Wang, "Selective Solid-Phase Extraction and Analysis of Trace-Level Cr(Iii), $\mathrm{Fe}(\mathrm{Iii}), \mathrm{Pb}$ (Ii), and $\mathrm{Mn}$ (Ii) Ions in Wastewater Using Diethylenetriamine-Functionalized Carbon Nanotubes Dispersed in Graphene Oxide Colloids." Talanta, 146, 358 (2016)

33. Y. Sun, H. Zheng, C. Wang, M. Yang, A. Zhou, and H. Duan, "UltrasonicElectrodeposition of Ptpd Alloy Nanoparticles on Ionic Liquid-Functionalized Graphene Paper: Towards a Flexible and Versatile Nanohybrid Electrode." Nanoscale, 8(3), 1523 (2016).

34. W. Wu, Y. Li, P. Chen, J. Liu, J. Wang, and H. Zhang, "Constructing Ionic LiquidFilled Proton Transfer Channels within Nanocomposite Membrane by Using Functionalized Graphene Oxide." ACS Appl Mater Interfaces, 8(1), 588 (2016).

35. Y. Sha, X. Zhang, W. Li, W. Wu, S. Wang, Z. Guo, J. Zhou, and X. Su, "A Label-Free Multi-Functionalized Graphene Oxide Based Electrochemiluminscence Immunosensor for Uitrasensitive and Rapid Detection of Vibrio Parahaemolyticus in Seawater and Seafood." Talanta, 147, 220 (2016).

36. T. Xue, S. Jiang, Y. Qu, Q. Su, R. Cheng, S. Dubin, C. Y. Chiu, R. Kaner, Y. Huang, and X. Duan, "Graphene-Supported Hemin as a Highly Active Biomimetic Oxidation Catalyst." Angew Chem Int Ed Engl, 51(16), 3822 (2012).

37. F. Bedioui, S. Griveau, T. Nyokong, A. J. Appleby, C. A. Caro, M. Gulppi, G. Ochoa, and J. H. Zagal, "Tuning the Redox Properties of Metalloporphyrin- and Metallophthalocyanine-Based Molecular Electrodes for the Highest Electrocatalytic Activity in the Oxidation of Thiols." Physical chemistry chemical physics: PCCP, 9(26), 3383 (2007).

38. N. Pereira-Rodrigues, R. Cofre, J. H. Zagal, and F. Bedioui, "Electrocatalytic Activity of Cobalt Phthalocyanine Copc Adsorbed on a Graphite Electrode for the Oxidation of Reduced L-Glutathione (Gsh) and the Reduction of Its Disulfide (Gssg) at Physiological Ph." Bioelectrochemistry, 70(1), 147 (2007).

39. J. H. Zagal, S. Griveau, K. I. Ozoemena, T. Nyokong, and F. Bedioui, "Carbon Nanotubes, Phthalocyanines and Porphyrins: Attractive Hybrid Materials for Electrocatalysis and Electroanalysis." J Nanosci Nanotechnol, 9(4), 2201 (2009).

40. F. Bedioui, D. Quinton, S. Griveau, and T. Nyokong, "Designing Molecular Materials and Strategies for the Electrochemical Detection of Nitric Oxide, Superoxide and Peroxynitrite in Biological Systems." Physical chemistry chemical physics: PCCP, 12(34), $9976(2010)$

41. S. F. Peteu, T. Bose, and M. Bayachou, "Polymerized Hemin as an Electrocatalytic Platform for Peroxynitrite's Oxidation and Detection." Analytica chimica acta, $\mathbf{7 8 0}$ 81 (2013)

42. S. F. Peteu, B. W. Whitman, J. J. Galligan, and G. M. Swain, "Electrochemical Detection of Peroxynitrite Using Hemin-Pedot Functionalized Boron-Doped Diamond Microelectrode." Analyst. 141(5), 1796 (2016).

43. F. Bedioui, S. Griveau, and D. Comment on Quinton, "Electrochemical Detection of Peroxynitrite Using a Biosensor Based on a Conducting Polymer-Manganese Ion Complex". Anal Chem, 83(13), 5463; author reply 5465 (2011).

44. C. Amatore, S. Arbault, D. Bruce, P. de Oliveira, L. M. Erard, and M. Vuillaume, "Characterization of the Electrochemical Oxidation of Peroxynitrite: Relevance to Oxidative Stress Bursts Measured at the Single Cell Level." Chemistry, 7(19), 4171 (2001).

45. D. Quinton, A. Girard, L. T. Thi Kim, V. Raimbault, L. Griscom, F. Razan, S. Griveau, and F. Bedioui, "On-Chip Multi-Electrochemical Sensor Array Platform for Simultaneous Screening of Nitric Oxide and Peroxynitrite." Lab Chip, 11(7), 1342 (2011).

46. S. Peteu, P. Peiris, E. Gebremichael, and M. Bayachou, "Nanostructured Poly(3,4Ethylenedioxythiophene)-Metalloporphyrin Films: Improved Catalytic Detection of Peroxynitrite." Biosens Bioelectron, 25(8), 1914 (2010).

47. W. S. Hummers and R. E. Offeman, "Preparation of Graphitic Oxide." J Am Chem Soc, 80, 1339 (1958).

48. M. Feelisch, J. Ostrowski, and E. Noack, "On the Mechanism of No Release from Sydnonimines." J Cardiovasc Pharm, 14. S13 (1989).

49. D. Yang, A. Velamakanni, G. Bozoklu, S. Park, M. Stoller, R. D. Piner, S. Stankovich, I. Jung, D. A. Field, C. A. Ventrice, and R. S. Ruoff, "Chemical Analysis of Graphene Oxide Films after Heat and Chemical Treatments by X-Ray Photoelectron and MicroRaman Spectroscopy." Carbon, 47(1), 145 (2009)

50. N. Li, Z. Geng, M. Cao, L. Ren, X. Zhao, B. Liu, Y. Tian, and C. Hu, "WellDispersed Ultrafine Mn 3 O 4 Nanoparticles on Graphene as a Promising Catalyst for the Thermal Decomposition of Ammonium Perchlorate." Carbon, 54, 124 (2013).

51. W. C. A. Koh, J. I. Son, E. S. Choe, and Y. B. Shim, "Electrochemical Detection of Peroxynitrite Using a Biosensor Based on a Conducting Polymer-Manganese Ion Complex." Analytical Chemistry, 82(24), 10075 (2010).

52. Z. X. Liang, H. Y. Song, and S. J. Liao, "Hemin: A Highly Effective Electrocatalyst Mediating the Oxygen Reduction Reaction." J Phys Chem C, 115(5), 2604 (2011). 